\title{
Reinvigorating Community Literature through Translating Orality and Culture
}

\author{
SAHDEV LUHAR
}

India is a land of diverse communities speaking numerous indigenous tongues. All these communities still have a living tradition of oral narrations. However, due to the failure of intergeneration transfer of the oral narratives in these communities and the lack of an agency that can script their indigenous dialects into written form led to their extinction. Though the linguistics define the term 'dialect' distinctively, the present paper uses the plural term 'dialects' or 'tongues' as synonymous to 'languages.' According to G N Devy, who led the People's Linguistic Survey of India (2010) from the front, there is an urgent need of preventing this future extinction by documenting and translating these oral narratives. Documentation of these narratives for the purpose of translation would create a rich corpus of community literature, and their translation into English (or into the larger Indian languages) would enhance the intercommunity access resulting into a better understanding of these communities. More importantly, their documentation and translation may succeed in preventing the possible extermination of languages and would strengthen the indigenous knowledge systems. This paper tries to suggest a possibility of preventing extinction of indigenous tongues of different communities through documentation for the purpose of translation. It also shows how these translations can reinvigorate the idea of community literature which is in fact vital for literary and geographic identities. It also addresses the problem of translating orality and culture that one may come across in such undertakings.

Keywords: community literature, documentation, translation, orality, culture, identity.

The colonial encounters have often resulted in destruction of many native cultural traditions. Contrary, they are also proved to be helpful in perpetuating certain traditions, albeit differently. The linguistic imperialism as a consequence of these encounters has obliterated many indigenous spoken Indian languages. It caused a danger to many indigenous languages-traditions. Language is a tool; if it can enslave the people, it also has power to make the master. There are ample possibilities of reversing the linguistic imperialism and reinvigorating the dying indigenous languages-traditions. Foremost among these possibilities is 'translation.' Translation of the different cultural 
traditions in the different language/s not only lengthens the life of those traditions but imparts them a new appearance. It also documents the Target Language (TL, henceforth) as a reference for those reading translation in the Source Language (SL, hereafter), thus, it archives the indigenous languagestraditions.

According to a survey, People's Linguistic Survey of India (PLSI), total "220 Indian languages have disappeared in the last 50 years, and that another 150 could vanish in the next half century as speakers die and their children fail to learn their ancestral tongue" (Kumar 2016). Total 10 per cent of the world's endangered languages are spoken in India. Many of these languages are spoken by the nomadic communities of India who migrate from one place to another. If we fail to protect these languages, it is sure that the cultural traditions these languages have nourished will die forever along with the thousands of the indigenous words they have given birth to. The paper attempts to show how translation can save these dying languages by transcribing them into the written scripts. Transcribing these languages for the purpose of translations into English language (or other Indian languages) will also empower these languages by expanding their reach. (It may seem paradoxical to take the help of a language that endangered the source language, however it is possible.) We should not forget that certain languages (for example English and French) were once upon a time were considered vernaculars but now they are enjoying heydays. We need to save these languages mainly for the purpose of protecting the throbbing cultural traditions embedded in these languages.

Since terms like 'language', 'dialects' and 'tongues' are used frequently in this paper, it is important to state their implications at the outset only. Though linguists define the term 'dialect' as a variety of language that is different from the other varieties of the same language by its pronunciations, vocabulary, discourse conventions, and other linguistic features, the present paper uses the plural term 'dialects' or 'tongues' as synonymous to 'languages.' Both 'language' and 'dialect' are ambiguous terms. Einar Haugen, in his essay 'Dialect, Language, Nation', observes that these terms "represent a simple dichotomy in a situation that is almost infinitely complex" (Haugen 1966: 922). He admits that "the use of these terms has imposed a division in what is often a continuum, giving what appears to be a neat opposition when in fact the edges are extremely ragged and uncertain" (ibid: 922). Looking back to the origin of these terms, Haugen tries to define them as follows:

In a descriptive, synchronic sense, "language" can refer either to a single linguistic norm, or to a group of related norms. In historical, diachronic sense "language" can either be a common language on its way to dissolution or a common language resulting from unification. A "dialect" is then any one of the related norms 
comprised under the general name "language," historically the result of either divergence or convergence (ibid: 923).

He further states that "In general usage it therefore remains quite undefined whether such dialects are part of "language" or not. In fact, the dialect is often thought of as standing outside the language. ... As a social norm, then, a dialect is a language that is excluded from polite society" (ibid: 924-5). Such observations of Haugen make it clear that to differentiate 'language' and 'dialect' is a perplexing task. Hence, the use of the word 'dialect' in this paper is limited to those languages that are considered marginalised or in Haugen's words 'excluded from the polite society' (ibid: 925). It is important to mention here that the languages too have sociocultural hierarchies as humans have. The hierarchy of languages is determined on the basis of the hierarchy among the speakers of those languages. For example, if a person speaks Sanskrit language, he will be considered a pundit; if a person speaks the English language, he will be considered a global citizen; similarly, if a person speaks Bhili language, he will be considered a tribal and will be treated as a tribal. Further, it is the State that determines the status of language as a 'language' or a 'dialect.' The status as a 'language' is a political construct. The 'dialect' that is supported by the State becomes 'language.' Contrary, the 'language' that does not receive support from the State becomes 'dialect'. Thus, it is the State that decides the status of a language as 'standard' or 'marginal.'

This paper is divided into three sections: (i) Translating orality and culture (ii) Idea of community literature, and (iii) What is the way forward? The first section - Translating orality and culture covers the theoretical ideas with regard to the problems of translating orality and culture; the second section deals with the idea of community literature; and finally, the third section discusses the reasons and possible ways of saving such endangered indigenous languages.

\section{Translating Orality and Culture}

The year 1990 marked an exemplary shift in the field of Translation Studies. It refuted the popular linguistic notion of translation as "substitution of TL [i.e., Target Language] meanings for SL [i.e., Source Language] meanings" as promulgated by JC Catford's book A Linguistic Theory of Translation: An Essay in Applied Linguistics (1965) (Trivedi 2007: 278). The claims of several linguists ${ }^{1}$ who consider Translation Studies as a subtype of Linguistics and who believe that translation is a transaction between two languages were also questioned. This unique idea was brought in by the publication of a jointly written chapter by Susan Bassnett and Andre Lefevere, entitled as "The Cultural Turn in Translation Studies", in their book Translation, History

\footnotetext{
${ }^{1}$ These linguists are Roman Jakobson, Eugene Nida, Peter Newmark, Werner Koller, Jean-Paul Vinay, Jean Darbelnet, and Kitty M. van Leuven-Zwart.
} 
and Culture (1990). The mechanical substitution theory of translation was rejected in this chapter and claimed that translation, instead, is "a more complex negotiation between two cultures" (ibid: 280). This cultural turn shifted the focus of translation from the linguistic properties to the culture in which the text is to be (re)constituted. The 1990s, along with the rise of Translation Studies, also witnessed the further growth of an influential field of study known as Cultural Studies. Though these two disciplines had no discernible overlap or interconnection, Bassnett and Lefevere endeavoured to bring them closer in their new book Constructing Cultures (1998). The final chapter of the book, "The Translation Turn in Cultural Studies," addresses certain pertinent questions which have hitherto remained unanswered by merging these two "interdisciplines", as they called them (Bassnett \& Lefevere 1998: 138). They believed that these interdisciplines had moved beyond their "Eurocentric beginnings" to enter into "a new internationalist phase" (ibid: 138). They ascertained four common agendas that Translation Studies and Cultural Studies could together address: (i) "investigation of the acculturation process that takes place between cultures and the way in which different cultures construct their images of writers and texts," (ii) identifying "the ways in which texts become cultural capital across cultural boundaries," (iii) exploration of "the politics of translating", and (iv) "pooling of resources to extend research into intercultural training and the implications of such training in today's world" (ibid:138).

Bassnett and Lefevere opined that the study of the translation, like the study of culture, needs "a plurality of voices"; likewise, the study of culture "always involves an examination of the processes of encoding and decoding that comprise translation" (ibid: 138-39). This idea of joining the forces of Translation Studies and Cultural Studies was pragmatically difficult. Despite all the commonality of ground and direction pointed out by Bassnett and Lefevere, there is one fundamental difference between these interdisciplines while Cultural Studies always operates in one language, i.e., English and its obtrusive complex variety called 'theory', Translation Studies, however theoretical it may be, operates in two languages and only one of which may be English (Trivedi 2007: 278). The 'cultural turn' in translation studies seemed an act of "transformative redefinition", whereas the translation turn in cultural studies still remains an "unfulfilled desideratum" (ibid: 278).

Lefevere was not the first to view the translation as part of larger cultural context. Earlier, Itamar Even-Zohar's polysystem theory did the same albeit in the literary sphere. Lefevere's theory differentiated translation from a pure linguistic activity. It widened the implication of the term 'translation' and opened the vistas of translation for retellings and adaptations as well. Any act of conscious or unconscious transformation now becomes the area of Translation Studies. A film adaptation of a literary text, any act of interpretation, communication in the multilingual world, machine translation, transcribing oral into written, etc. came to be construed as fields of Translation Studies. For Lefevere, translation is a cultural act that has been 118 
influenced by the outer considerations. In Translation, Rewriting and Manipulation of Literary Fame (1992), Lefevere sees translation as the "most obviously recognizable type of rewriting" that has potential to "project the image of an author and/or those works beyond the boundaries of their culture of origin" (Lefevere 1992: 9). He opines that "on every level of the translation process, it can be shown that, if linguistic considerations enter into conflict with consideration of an ideological and/or poetological nature, the latter tend to win out" (ibid: 39). The translation theorists like Maria Tymoczko, in her essay "Post-colonial Writing and Literary Translation", depicts a similarity between the literary translators and the postcolonial authors writing in the colonisers' language for the foreign audience. According to her, both literary translator and postcolonial author are faced with the task of transposing a culture across a culture and (a) language(s), and they both face choices that are certainly ideologically driven (Bassneet \& Trivedi 1999: 24). Michael Cronin, in his Translating Ireland (1996), focuses on the role of translation in the Linguistic and political battle between the Irish and English languages examining how Irish translators throughout history have discussed and presented their work in prefaces, commentaries, and other writings (Munday 2012: 206). He uses the metaphor of translation to reflect the colonial control. He says that "translation at a cultural level - the embrace of English acculturation - is paralleled by translation at a territorial level, the forcible displacement and movement of populations" (Cronin 1996:49). As Niranjana, in her Siting Translation (1992) would put it, "Translation as a practice shapes, and takes shape within, the asymmetrical relations of power that operate under colonialism" (Niranjana 1992: 2). She concentrates on how translations into English were being used by the colonial power to a rewritten image of the East that has come to stand for the truth. For her, translation is one of the discourses that tell that the "hegemonic apparatuses" belong to "the ideological structure of colonial rule" (ibid: 33). Eric Cheyfitz also sees translation as an aggressive act that attempts to equate the inequality between literary cultural systems.

While translating a text from SL to TL, one frequently comes across two greater challenges, i.e., of translating culture and orality. The marginalised cultures, which use dialects as a means of communication, in many cases do not have their own script. Hence, they have to depend on the script used by the dominant culture(s) before it could be translated into TL. It clearly means that translation of marginalised cultural text(s) requires a two-stage translation - first into the script of recognised language and then into TL (which is also a language of a dominant group). This undoubtedly means that a translator must have mastery over linguistic parallelism and cultural considerations. As Bassnett would say in her essay "Culture and Translation", the 1990s signalled a shift from a more formalist approach to translation to a greater emphasis on extra-textual factors (Bassnett 2007: 13). Translation Studies needed "to be on broader issues of context, history and convention" and not "on debating the meaning of faithfulness in translation or what the term 
'equivalence' might mean" (ibid: 13). Apart from such extra-textual factors, a translator also faces certain pragmatic difficulties while translating a culture specific text into another culture or language. Translating as an act and translation as its result always demonstrates certain cultural implications. Since a language or a dialect is always culture-specific, a translator may face some problems while translating certain culture-specific terms into the TL. The translator finds difficulty in translating culture-specific words, phrases, idioms, slangs, and proverbs because there is no one to one correlation between one culture and another or one language and another. While translating from SL to TL, the translator always faces the problem of the availability of the equivalent words. It is only through a socio-cultural matrix, the translator can translate the culture-specific text (SL) into another language (TL).

Another great challenge for a translator is the translation of orality. Orality, as Paul Bandia puts it, is a "representation of otherness, the assertion of marginalized identities through a variety of art forms" (Bandia 2015: 125). In this sense, orality is a literary representation of oral-spoken discourse. It, thus, gives a voice to hitherto unheard marginalised or subaltern voices. Walter J. Ong, in his Orality and Literacy (1982), has a different notion of orality. He perceives orality as "managing knowledge and verbalization in primary oral cultures (cultures with no knowledge at all of writing) and in cultures deeply affected by the use of writing" (Ong 1982: 1). He proposes that primary orality and primary oral cultures ("those untouched by writing in any form") are related with a recurrent recourse to mnemonics and are by nature "additive rather than subordinate", "aggregative rather than analytic", "redundant or "copious", "conservative or traditionalist", "close to the human lifeworld", "agonistically toned", "empathetic and participatory rather than objectively distanced", "homeostatic", and "situational rather than abstract" (ibid: 36-48). Thus, the standpoints adopted by Bandia and Ong unmistakably suggest that orality is more complex than the people believe it to be. If one takes in account these views of Bandia and Ong, he or she would certainly realise that while translating orality a mere translation of words is not enough: one has to translate the orality in a way that it echoes the identity of the marginalised groups. Ong's perception also hints at a challenge of translating orality: since the orality is the source of knowledge in many cultural groups, while translating the orality the translator must try to retain the traditional knowledge that the orality inherits in it. In addition to these challenges, the translator should focus on the different features of the orality (here as proposed by Ong) and should confirm these features in the translated version of the orality. Failure in this task itself mean that the translator has failed in his task.

According to Sitakant Mahapatra, orality and oral culture rest on the communitarian togetherness and the emphasis on the sacral (1993: 49). He adds that the tradition that orality builds "is intimately linked to ultimate questions of life and death, the intricate questions of existence and is thus 120 
linked to the world of faith and belief, in short, the sacral world" (ibid:49). Such views of Sitakant Mahapatra add more responsibilities to the tasks of the translator of the orality. While translating orality, the translator has to confirm that he succeeds in creating the communal togetherness among the members of community to which orality belongs to. The translated version of the orality should generate the feeling of belongingness among the members of the community. It should also retain the idea of sacral and should answer all the questions related to life, death, existence, faith, and belief in the same way the orality does. Orality is a great repository of information about a community that owns it. It is an archive of mythical, legendary and historical past of the community. It constitutes its own modes of expression and transmission. Orality offers numerous examples that can sustain contemporary social order. It articulates distinct cultural identity of the community formed by the social practices, religious beliefs, ethical values, and customs. It may take up the form of protest and may voice concerns of reform. Soumen Sen and Desmond L. Kharmawphlang observe that orality is the great highway of information where an exciting intersection of ideas, forms, and styles takes place at different levels, creating processes and dialogues with inter-linkages between form and content, genre and theme, visual and aural, local and regional, traditional and contemporary (Sen \& Kharmawphlang 2007: 5) The failure of inter-generation transfer of the orality has caused a condition of its extinction. Hence, orality should be preserved in written form and preserving orality in a written form will create a cultural corpus and will enliven the cultural tradition of a community for a longer time. Any act of transferring orality onto paper may also be conceived as translation. ${ }^{2}$ Such an act of translation requires an in-depth knowledge of the culture of a community. Since orality mostly exists among the unrecognised languages or dialects, it is the task of the translator to reconstruct orality without losing its essence while transferring it to written form from the oral.

\section{Idea of Community Literature}

There are thousands of the communities across the world and most of these communities have their own tradition of oral narratives. The oral literature of these communities is a great cultural heritage that may help us to understand their indigenous knowledge systems. In Indian context, the idea of 'Community Literature' may refer to a body of literature by the diverse communities in India that speak thousands of indigenous tongues. These literatures may narrate tradition or modernity. It narrates the tradition by recalling the memories of the days that have gone by, and it describes the

\footnotetext{
${ }^{2}$ However, terming this kind of transfer as 'translation' may trigger reactions from those who have labelled it as 'transcription', 'transmutation', 'adaption', 'transformation', and 'transliteration'. However, there are many who proposed these terms under a single umbrella term - 'translation'.
} 
modernity by recounting the changes that have taken place from time to time in the cultural traditions.

India is a land of numerous linguistic communities. These communities are found even within the chief spatial linguistic units. For example, Gujarat ${ }^{3}$ is a chief spatial linguistic unit for Gujarati language, and within Gujarat there are hundreds of "sub-linguistic" communities. These communities are "sublinguistic" because they have less number of the speakers of their own languages than the speakers of Gujarati language. The members of a sublinguistic community generally share common cultural traditions and have a common way of life. Culturally, the speakers of these tongues are considered marginalised because of their numbers, their distinct life style, and the occupations they are engaged in. Because of their population, they are also considered politically insignificant. Though culturally and politically these communities may seem insignificant, they have immense literary importance. Many communities like wandering ironsmiths (Gaduliya Lohar), snakecharmers (Vadee), Bhavai players, Chamatha, Banzaras, Turi, Kothada, and others have their indigenous tongues and way of life. ${ }^{4}$ All these communities have a rich corpus of oral literature in the form of tales, songs, drama, dancesongs, proverbs, puzzles, etc. They transmit their oral literature to their next generations through oral communication. Since they do not have a recognised script to record the oral traditions, their literature is on the verge of extinction. The failure of inter-generation transfers of the oral literatures of these communities and absence of an agency that can script their indigenous dialect into written form has caused a condition of its extinction. These oral literatures can be saved by documenting, analysing, digitalising, translating, and archiving.

\section{Community, Tribe, and Folk: A Conceptual Understanding}

Before proceeding further, let us first understand three complex terms 'community', 'tribe', and 'folk'. The understanding of these terms would help us to comprehend the idea of 'Community Literature' in a better way.

\section{Community}

Community is a multifaceted term. The word community is made of two Latin words i.e. 'cam' means 'together' and 'munis' means 'serve'. So, the idea of 'serving together' constitutes the meaning of 'community' in etymological sense. In our common understanding, the term 'community' refers to "the condition of sharing or having certain attitudes and interests in

\footnotetext{
${ }^{3}$ Gujarat is one of the prominent states of India located in the western part. The latitudinal and longitudinal extents of the state are $20^{\circ} 01^{\prime} \mathrm{N}$ and $24^{\circ} 07^{\prime} \mathrm{N}$, and $68^{\circ} 04^{\prime} \mathrm{E}$ and $74^{\circ} 04^{\prime}$ E respectively.

${ }^{4}$ All these are wandering communities of Gujarat. It has been estimated that there are total 28 nomadic communities in Gujarat. Source: https://sje.gujarat.gov.in/ddcw/showpage.aspx? contentid=1730\&lang=english
} 
common", whereas folk means "relating to the traditional art or culture of a community or nation" (English Oxford Living Dictionary ). It can be more concretely defined as "a group of the people living in the same defined area sharing the same basic values and organisation" or as "a group of the people sharing the same interests" (Rifkin et al. 1988: 933). Community is "an informally organised social entity which is characterised by a sense of identity." The concept of community is very broad. The members of the community may share the same neighbourhood or a region. They may share a common ethnicity, religion, cultural identity, gender, gender identity, nationality, immigration status, disability, profession, political affiliation, values, interests, or any other identity.

For sociologists, "community is a collection of people in a geographical area". Three other elements that are also taken into account while discussing the idea of community in sociological sense are:

(a) Communities may be thought of as collections of people with a particular social structure; there, therefore, collections which are not communities. Such a notion often equates community with rural or preindustrial society and may, in addition, treat urban or industrial as positively destructive.

(b) A sense of belonging or community spirit.

(c) All daily activities of a community, work and non-work, take place within the geographical area; it is a self-contained (Mallick 2013: 4).

Of course, there are some other sociologists as well who have added some more elements while discussing the idea of community. For many sociologists of the nineteenth century, the 'community' was a part of their critique of urban-industrial society. For them, communities were associated with all the good characteristics that have thought to be possessed by rural societies. On opposite, they considered that urban societies represented the destruction of community values. However, it became clear that communities cannot be divided into rural or urban communities or non-communities. Instead the sociologists proposed a rural-urban continuum that can accommodate various features/elements of social structures to understand the concept of community. According to Amitai Etzioni, community has two characteristics: "(a) A web of affect-laden relationships among a group of individuals, relationships that often crisscross and reinforce one another (as opposed to one-on-one relationships); (b) A measure of commitment to a set of shared histories and identities - in short, a particular culture" (ibid: 4).

Nowadays, the term 'community' is used to indicate a sense of identity, or belonging that may or may not be tied to geographical locations. This leads to a more clear idea that a community is formed when people have a reasonably clear idea of who has something in common with them and who has not. That

\footnotetext{
${ }^{5}$ This definition of community is quoted in Tim Berthold, Alma Avila, Jennifer Miller edited volume Foundations of Community Health Workers, San Francisco: Jossey-Bass, 2009. (p.534).
} 
is why Elijah Anderson states that "communities are, therefore, essentially mental constructs, formed by imagined boundaries between group" (ibid: 4).

Tribe

As a part of social classification in the colonial era, the term 'tribe' has emerged as an anthropological category. This sense makes it different from the pre-modern Indian concept of jati. Though both these term appear synonymous, the later lack the anthropological connotations that the term 'tribe' inherits (Baruah 2009: 78). In simple words, the term 'tribe' refers to specific patterns of economic and socio-cultural modes of life. To modern anthropologists, 'tribe' is also a stage in social development. It has been assumed that "hunting and gathering society would develop into 'tribal' formations, which then would develop into state societies, whether republic or monarchy" (ibid: 78). Baruah reflects that "tribe' is a stage in evolution of human society from primitive to modern. Thus, vis-à-vis modern society, tribal stage came to be seen as primitive, i.e. in a stage of social development earlier to modern society" (ibid: 78). However, as Baruah admits, placing 'tribe' on an evolutionary ladder is indeed a shaky task (ibid: 78). It should be understood in as "a certain mode of existence among other modes with its own codes" (ibid: 78). Tribe should be better understood in connections with codes such as kinship relations, cultural narratives, strategies of existence, and political formations.

Folk

Folk is a broad term. It includes the meaning of term 'community' in it. Folk commonly refers to the traditional inhabitants of the tribal areas. Tribal communities are majorly considered folk communities. The anthropological perception of folk as a primitive group associates the idea of folk to the tribal communities. The term 'folk' is derived from the German tern 'volk' which has a more dynamic meaning than the English equivalent, 'folk'. The term 'volk' has its root in the late nineteenth and the early twentieth century word, 'volkskunde', which referred to the academic study of the collective German history. Hank Levin observes that the academic term 'volkskunde' gradually involved into "a catalyst of nationalist propaganda which masked blatant and sinister political agenda" (Levin n.d.:n.p.); he adds that as the nineteenth century progressed, the "Germans interpreted the Volk as a rallying point, which enabled them to see themselves as a superior native race and set themselves apart from other peoples" (ibid). This idea of Volkskunde led to see the Jews as the antithesis of the Volk values. The Jews appeared to the German as the biological or the social 'other'. Thus, influenced by the German term 'Volk', the English word 'folk' constitutes a dichotomy - 'self' and 'other'.

The idea of folk originated in the nineteenth-century when it meant "a group of people who constituted the lower stratum, the so-called vulgus in populo - in contrast with the upper or elite of that society" and was 124 
considered "the uncivilized element of a civilized society" (Dundes 1980: 2). However, the idea of folk occupied an upper level than the savage or primitive society. So, on the evolutionary ladder, the folk means a group of the people who are neither highly civilised nor so primitive-savage. Gradually the ideas of "peasant" or "illiterate in literature society" were constituted to differentiate folk from the civilised and the savage. If folk has to be defined in relation to the civilised society, the idea of non-literate, illiterate, and literate may pop up. While the savage-primitive group is generally believed to be non-literate or pre-literate, the folk is considered as illiterate, rural, and of lower stratum; and on the other hand the civilised-elite is considered as literate, urban, and of a high stratum. Therefore, in the cultural evolutionary sequence of savagery, barbarism, and civilisation, which all the cultural groups are supposed to pass by; the folk can be broadly considered somewhere in between savagery and civilisation.

For the purpose of this paper, all those marginalised communities speaking indigenous dialects, living a nomadic life, and having a tradition oral narrative are considered one and are put under the umbrella of 'community literature'. So, the word "community" in the phrase "community literature" is used to refer to a broad category of marginalized nomadic communities that use local dialects. Since the present paper limits the scope of community literature to only the marginalised nomadic communities, the community literature may be understood as different from the folk literature that considers all the oral narratives as its corpus. The phrase 'folk literature' is often used to designate the body of oral literatures. The use of umbrella term, 'folk literature', does not clearly attribute its belongingness to any specific community. Similarly, the phrase 'tribal literature' refers to a body of oral/written narratives of the different tribes. ${ }^{6}$ But the idea of community literature arouses a notion that the oral literature under discussion only belongs to a certain group, i.e. a nomadic group. Thus, it may distinguish itself by adding a sense of belongingness that folk literature generally does not do (except when it is used specifically). Similarly, 'tribal literature' hints at oral or written literatures of different tribal communities. Nowadays, it has become a trend to pen down literary narratives in the languages of tribal communities. So, 'tribal literature' does not necessarily hint at a body of oral narratives. Among the three terms discussed above, 'community', 'tribe', and 'folk', the term 'community' seems to be more suitable for reflecting the connotations such as shared histories, identities, and belongingness and that is the main reason why, in this paper, 'community literature' is considered as an apt label than others.

\footnotetext{
${ }^{6}$ Some nomadic communities of Gujarat are also included in the list of "Schedule Tribes" (ST) and "Schedule Castes" (SC). For example, the nomadic communities like 'Kathodi', 'Kotvadiya', 'Vitodiya' are recognised as STs and some other nomadic communities like 'Garudi' and 'Turi' are recognised as SCs In short, the idea is that 'tribe' and 'nomad' are not the fix categories.
} 
Without any doubt, there are many things that are common between folk literature and community literature. Folk literature can be defined as the traditional, imaginary, marginalised, and countrified literature of a certain cultural group which is set in the time immemorial and has come to this community via the oral transmissions which may be now available in speech or in print. ${ }^{7}$ Thus, community literature and folk literature are similar in terms of orality. However, community literature has other distinct qualities. It is largely available in oral form. Due to the lack of proper awareness, the members of the communities, who are also the carriers of the oral traditions, do not document their orality. Of course, those who possess a good corpus of oral songs and tales (and other oral forms) are commonly old and majority of them are illiterate. Since this literature is always dialectal, it does not have its own script. If these are to be translated, one may translate them using the script of a language which is close to the dialect. Community literature is popular among the members of the community it belongs to. Majority of the songs and tales have reached them through the inter-generation transfers, and therefore, these oral literary forms maintained their similarity within a linguistic community living across the places. As most of the oral literature has a purpose of teaching cultural, social and ethical values, it can be noticed that community literature teaches even the serious things in light-hearted manner. Naturally, while narrating episodes of war, heroic deeds, adventures and struggles of their heroes, it attains a serious outlook. Community literature is greatly influenced by the classic epics and their fragments. Community literature presents different perceptions of life and the world as seized by the different communities.

\section{What is the Way Forward?}

Before addressing the query raised here it is essential to know why community literature is important to us. The community literature is not merely a literature produced by different communities but is an essential tool to understand the cultural dynamics of these communities. It records the life, traditions, customs, beliefs, and aspirations of the people from those communities. It opens up a scope to understand the people from different communities. Through community literature, we can rediscover the historically forgotten facts of their cultural history. It gives us a chance to peep into the mindset of these communities and the ethos they have held up to now. If we want to understand India in a better way, we must understand hundreds of such communities which have been left out in the process of modernisation. If we want to understand our native culture, we must search its rudiments in the lives of these simple people. Perhaps, those who carry the oral tradition may not have the knowledge of literary traditions and devices but their oral narrations are still alive throbbing with warm blood. Community

\footnotetext{
${ }^{7}$ This concept of folk literature is developed by my reading of the essay "The Idea of Folklore: An Essay" (1983) by Dan Ben-Amos.
}

126 
literature may truly fill in the gap that has remained unfilled because the absence of literature by those who have words but no script.

Translation has the power to spread community literature across the world. India has a rich corpus of literature having the potential to be the World Classics but due to insufficient translation, those are yet to be showcased to the world. Extinction of local languages also means death of the cultural traditions. It takes hundreds of the years for any community to develop its own distinct vocabulary. But such extinction of languages creates a roadblock to the community members who has struggled for many years for the development of their language and the culture. Because of the rapid modernisation that has taken place in India, the first half a decade of the twenty-first century was more deadly for indigenous languages.

It will be hyperbolic to suggest that the real need of creating a huge corpus of indigenous literatures of India that has hitherto remained unnoticed is more than ever in decelerating the process of their extinction. We can also spread awareness regarding indigenous language and their literary richness. Through translation of these literatures into English or other Indian languages, a new life and a new appearance can be given to them. Such endeavour may help us to save more than a hundred of Indian languages which do not have their own scripts.

To conclude, it can be asserted that the idea and revitalisation of the community literature is a need of the hour to conceptualise the 'Indian culture' as a whole. The marginalised cultural groups have often remained unnoticed because of the indigenous and unrecognised languages they speak. Such endeavour will not only give them an identity but also ensure muchneeded cultural dignity.

\section{References}

BANDIA, PAUL F. 2015. Introduction: Orality and Translation. Translation Studies 8(2). 125-127.

BARUAh, MANJEeT. 2009. Tribal, Folk, and Classical Cultures: Definitions and Interrelationship. Folklore and Culture: Conceptual Perspectives. New Delhi: IGNOU.

BASSNETT, SusAn, and ANDRE LEFEVERE. 1998. Constructing Cultures: Essays on Literary Translation. Clevedon: Multilingual Matters.

BASSNETT, SUSAN, and HARISH TRIVEDI. (eds.) 1999. Post-Colonial Translation: Theory and Practice. London and New York: Pinter Publisher.

BASSNETT, SUSAN. 2007. Culture and Translation. A Companion to Translation Studies. Clevedon: Multilingual Matters.

CRONIN, MiCHAEL. 1996. Translating Ireland: Translation, Languages, Cultures. Cork: Cork University Press. 
DUNDES, ALAN. 1980. Interpreting Folklore. Bloomington: Indiana University Press.

English Oxford Living Dictionary. 2017. Online: https://en.oxforddictionaries. com.

Haugen, EINAR. 1966. Dialect, Language, Nation. American Anthropologist 68(4). 922-935. Online: http://www.jstor.org/stable/670407?origin=JSTOR - pdf.

KuhiwCZAK, PiOTR, and KARIN LitTAu. (eds.) 2007. A Companion to Translation Studies. Clevedon: Multilingual Matters.

KUMAR, GUDIPATI RAJENDRA. 2016. India Rapidly Losing its Languages. The Hans India. Online: http://www.thehansindia.com/posts/index/NewsAnalysis/2016-07-28/India-rapidly-losing-its-languages/245117.

LEFEVERE, ANDRE. 1992. Translation, Rewriting and Manipulation of Literary Fame. London: Routledge.

LEVIN, HANK. 2017. Anti-Semitism in German 'Volk' Culture: Propaganda through the Pen and Screen .Online: https://earlham.edu/media/1683301/ anti-semitism-in-german-volk-culture.pdf.

Mahapatra, SitAKANT. 1993. Beyond the Word: The Multiple Gestures of Tradition. Delhi: Motilal Banarsidass Publishers Pvt. Ltd.

MALLICK, SAMBIT. 2013. Institution, Community and Association. An Introduction to Sociology. Online: https://nptel.ac.in/courses/109103023/ download/Lecture\%204.pdf.

MundAY, JEREMY. 2012. Introducing Translation Studies: Theories and Applications. New York: Routledge.

NiRANJANA, TEJASWINI. 1992. Siting Translation: History, PostStructuralism and the Colonial Context. Berkeley: University of California Press.

Ong, Walter J. 2002. Orality and Literacy: The Technologizing of the World. London: Routledge.

RIFKIN, S. B; Muller F.; and BiCHMAN W. 1988. Primary Health Care: On Measuring Participation. Social Science \& Medicine 26(9). 931-40.

SEN, SOUMEN, and DESMOND L. KHARMAWPHLANG. (eds.) 2007. Orality and Beyond: A North-east Indian Perspective. New Delhi: Sahitya Akademi.

ST-PIERRE, PAUL, and PRAFUlla C. KAR. (eds.) 2007. Translation: Reflections, Refractions, Transformations. Amsterdam: John Benjamins Publishing Company.

TRIVEDI, HARISH. 2007. Translating Culture vs. Cultural Translation. Translation: Reflections, Refractions, Transformations. Amsterdam: John Benjamins Publishing Company. 